\title{
The cytoskeleton and its importance as a mediator of inflammation
}

\author{
K R Rogers, C J Morris, D R Blake
}

Cellular life by its very nature requires organisation and structure. Cells must, however, also have a degree of plasticity to perform varying cellular functions. The cytoskeleton possesses the required characteristics for both these properties.

The eukaryotic cytoskeleton is a complex three dimensional lattice radiating throughout the cytosol and nucleus which is made up of three distinct types of filament ${ }^{1}$ (table 1). There is, however, a vast array of other associated proteins, many of which have unknown function. The protein composition of the cytoskeleton is characteristic for a specific cell or tissue type, and provides the machinery required for cellular/tissue function. Within the cytosol these filaments provide a structural and an organising role. Many organelles, for example, have a close association with the various filament types. These include the mitochondria, Golgi apparatus, and endoplasmic reticulum. An intact cytoskeleton is essential for vital cellular functions, including vesicle/organelle transport, cell-cell interaction, cell extracellular matrix interactions through association with surface receptors, cell motility, and cell cycle. Despite the structural role of the cytoskeleton it

Table 1 Composition of the eukaryotic cytoskeleton

\begin{tabular}{|c|c|c|c|}
\hline Filament & Size (nm) & Subunit protein & Functions \\
\hline $\begin{array}{l}\text { Microfilaments } \\
\text { Microtubules }\end{array}$ & $\begin{array}{c}7 \\
25-39\end{array}$ & $\begin{array}{l}\text { Actin } \\
\text { Tubulin }\end{array}$ & $\begin{array}{l}\text { Structure, cell motility } \\
\text { Intracellular transport, } \\
\text { cell division }\end{array}$ \\
\hline Intermediate filaments & 10 & 20-30 different types & - \\
\hline
\end{tabular}

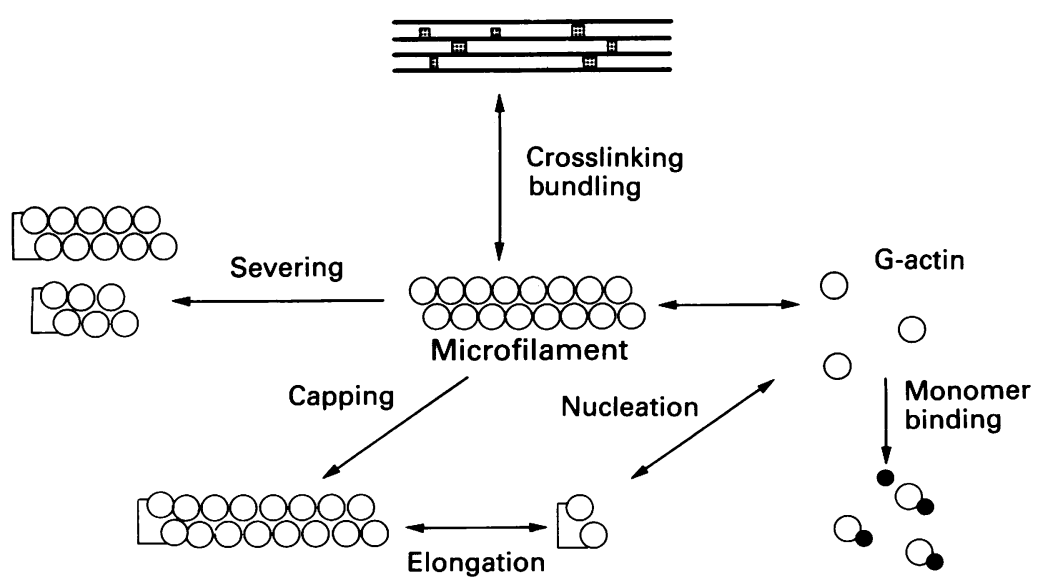

Microfilament structural processes.

is highly dynamic as cell function/activation requires rapid modification of cellular structure.

\section{Cytoskeleton structure/function MICROFILAMENTS}

Microfilaments are made up of actin monomers (43 kilodaltons). Actin is an astoundingly highly conserved protein and is therefore essential for cell survival. ${ }^{2}$ There are, however, various actin isoforms that occur in different cell types owing to phosphorylation and expression of different gene products. Three such isoforms, which can be distinguished by isoelectric focusing, are termed $\alpha, \beta$, and $\gamma$ in descending order of acidity. ${ }^{3}$ Actin is a globular protein but is not spherical. It has one ATP binding site and one high affinity binding site for divalent ions. Microfilament actin (F-actin) exists in equilibrium with a soluble monomeric actin (G-actin) pool and gives rise to the so called gel-sol transition. Filament formation proceeds in two steps: nucleation and elongation. ${ }^{4}$ Nucleation involves the formation of an actin oligomer and is slow. It is the major variable for actin assembly in vitro, and is thought to be an important regulatory step in vivo. Recent studies using microinjection have shown that the presence of nucleation sites does not necessarily lead to filament formation (see associated proteins below). ${ }^{5}$ Elongation is rapid and involves the addition of monomers to the nucleation site. ATP is hydrolysed when Gactin binds to the growing end of the filament. Microfilaments form a two-start, double stranded, right handed helix with an axial repeat of $36 \mathrm{~nm}$ (about 13 subunits). ${ }^{6}$ The monomer binding constant is different for each end of the filament, which gives it a definite polarity. There are also a large number of actin binding (or associated) proteins which regulate filament structural processes (figure). ${ }^{7}$

Capping Some proteins bind to the ends of the filament. This effectively stops further association of actin monomers and filament elongation.

Nucleation is a major regulatory step in filament formation. Proteins exist that regulate this process. Gelsolin, for example, binds two actin monomers and hence produces a site for filament formation. (Note, however, that gelsolin can have a paradoxical function, see below.)

Monomer binding Profilin is the best known member of this group, which regulates the 
number of monomers that are available for filament formation by binding them and thereby altering the equilibrium between monomer and filamentous actin.

Severing Some proteins bind to intact filaments and then cause them to break into two.

Cross linking This group forms bridges between more than one filament and can thereby form either networks - for example, filamin, or bundles-for example, villin (in stress fibres). Differential expression of these proteins will obviously have a dramatic effect on microfilament structure. It is also known that several important glycolytic enzymes (glyceraldehyde3-phosphate dehydrogenase, aldolase, and phosphofructokinase) are associated with microfilaments. Thus microfilaments may restrict enzymes involved in energy metabolism to different compartments. ${ }^{8}$ Microfilaments are essential for cell structure and morphology as the drug cytochalasin b, which disrupts microfilaments, causes fibroblasts to round. ${ }^{9}$ In nonmuscle cells they form an actin cortex on the cell periphery. This cortex is largely made up of stress fibres that have connections with the extracellular matrix through, for example, the fibronectin receptor. ${ }^{10}$ Microfilaments also form a power generating system to provide the force required for cell motility. Actin filaments can therefore be seen as extensive structures in the moving front of pseudopodia. Recent data have suggested a role for microfilaments in cell activation. Profilin not only binds actin but also polyphosphatidylinositol 4,5-bisphosphate $\left(\mathrm{PIP}_{2}\right)$. Phospholipase $\mathrm{C}$ converts $\mathrm{PIP}_{2}$ to inositol 1,4,5-trisphosphate $\left(\mathrm{IP}_{3}\right)$ and diacylglycerol, which are both second messengers that play a part in cell signalling. Profilin also regulates the phospholipase $\mathrm{C}$ conversion of $\mathrm{PIP}_{2}$ to $\mathrm{IP}_{3}$ and diacylglycerol. In an unstimulated cell 8:1 PIP $_{2}$ :profilin complexes are present, and hence the basal production of $\mathrm{IP}_{3}$ and diacylglycerol is low. After activation an increase in activity occurs and PIP $_{2}$ is broken down. ${ }^{11}$

\section{MICROTUBULES}

Microtubules are hollow cylinders with internal and external diameters of 15 and $25 \mathrm{~nm}$ respectively. ${ }^{12}$ The diameter of the filament is made up of about $15^{13} \alpha$ and $\beta$ tubulin monomers of molecular weights 56000 and 54000 which bind to form heterodimers. These proteins are highly conserved and characterised by a highly acidic $\mathrm{C}$ terminus with a large number of aspartic and glutamic acid residues. Each dimer contains two GTP binding sites but only one, the exchangeable (or E) site, which is located on the $\beta$ monomer, contains GTPase activity. The GTP in the non-exchangeable site remains unhydrolysed throughout polymerisation. This GTPase is activated on binding to the filament. Energy is therefore used for tubule formation and ATP does affect microtubules indirectly by affecting nucleation. The wall of the cylinder is made up of linear elements termed protofilaments, which are formed from tubulin subunits aligned in rows. ${ }^{14}$ The most common number of protofilaments in a microtubule is 13 .
Microtubule formation, as in the microfilament, occurs in two steps: nucleation, when a lag period occurs for oligomer formation, and elongation where subunits add directly to the growing polymer. ${ }^{15}$ Heterodimers bind to both ends of the filament, but at different rates-that is, they have different critical concentrations for dimer addition. Thus microtubules, like microfilaments, are polar. Their formation has also been linked to mitochondria where the 73 kilodalton heat shock protein and chaperonin protein are involved in oligomer formation. ${ }^{16}$ The in vitro assembly of microtubules is profoundly affected by two cations: magnesium and calcium. Millimolar quantities of magnesium are obligatory for filament formation, whereas even micromolar amounts of calcium are inhibitory. For this to happen, however, calmodulin must be present. Hence when the calcium concentration reaches submicromolar levels in the cell, microtubules disassemble. ${ }^{17}$ Microtubules radiate throughout the cytoplasm from the nucleus to the surface membrane and are extensively associated with the endoplasmic reticulum and Golgi apparatus. They, therefore, play a part in vesicle transport and endocytosis/exocytosis. Nacodazole, a microtubule disrupting agent, completely inhibits retrograde transport from the Golgi apparatus to the endoplasmic reticulum. ${ }^{18}$ During mitosis microtubules participate in the generation of spindle fibres from the centrioles, which are involved in movement of the chromosomes during cell division. ${ }^{19}$

\section{INTERMEDIATE FILAMENTS}

Intermediate filaments were first discovered as $10 \mathrm{~nm}$ filaments and originally thought to be degradation products of the other types of cellular filament. ${ }^{20}$ Intermediate filaments can be classified into five groups based on the sequence homology of the proteins from which they are constructed (table 2). ${ }^{21}$

These groups of intermediate filament proteins, of which 20 or so are known, are highly developmentally regulated. When a cell has differentiated it has a characteristic intermediate filament protein expression. Hence mesenchymal cells express vimentin, muscle cells express desmin, nerve cells express neurofilaments, and epithelial cell express cytokeratins. Some cells, however, possess no intermediate filaments. ${ }^{22}$

Intermediate filament proteins have a common basic subunit monomer structure consisting of three domains: the $\mathrm{N}$ terminus variable region, the central highly conserved 38 kilodalton region, and the $C$ terminus variable region. ${ }^{23}$

The central domain region possesses a large number of hydrophobic amino acids, which

Table 2 Classification of intermediate filaments

\begin{tabular}{ll}
\hline Type & \\
\hline I & Acidic keratins \\
II & Neutral/basic keratins \\
III & Vimentin, desmin, and glial fibrillary \\
acidic protein & Neurofilaments \\
IV & Lamins \\
V & \\
\hline
\end{tabular}


give the intermediate filament protein its characteristic insolubility at physiological ionic strength. It forms an $\alpha$ helix as its amino acid is a classical Kmef quasi heptad repeat sequence (a-b-c-d-e-f-g). This sequence is characteristic of several fibrous proteins. Seventy five per cent of the a and $d$ residues are apolar, whereas $b, c$, $\mathrm{e}, \mathrm{f}$, and $\mathrm{g}$ are often polar or charged residues. This favours a coiled-coil formation as the a and d residues are on the same side of each monomer helix, dimerisation occurring through hydrophobic bonding. Tetramers are formed which then produce $10 \mathrm{~nm}$ filaments by a poorly understood mechanism. Intermediate filaments can assemble in vitro without the presence of any other proteins and it is therefore reasonable to assume that all the information required for formation of intermediate filaments is present in the primary structure of intermediate filament proteins. Recent sequence data have shown that the $\mathrm{N}$-terminal and $\mathrm{C}$-terminal regions have variable sequence homology and size. These regions therefore characterise the intermediate filament protein.

The $\mathbf{N}$ termini of type III intermediate filament proteins are hypervariable and basic. Vimentin, for example, contains 15 arginine residues in this region and these are thought to take part in assembly of intermediate filaments. ${ }^{24}$ Quinlan et al have recently proposed that it is the spatial arrangement of charge that is important in formation of intermediate filaments. ${ }^{25}$

Intermediate filaments are not polar and there is only a very small pool of non-filamentous protein. ${ }^{26}$ In addition, intermediate filaments are not in equilibrium with this pool. ${ }^{27}$ Instead it appears that intermediate filaments are formed by two mechanisms, cotranslation around the nucleus and rapid formation from a small pool of monomers. ${ }^{28}$ This is in sharp contrast with microtubules and microfilaments and may have functional implications. Intermediate filaments radiate throughout the cytoplasm and make connection with the nucleus and the plasma membrane. ${ }^{29}$ The precise function(s) of intermediate filaments remains one of the unsolved enigmas in cell biology, though a number of suggestions have been made: mechanical integrators of space, cell regulation, and nuclear function. ${ }^{29-31}$ No experimental data have unequivocally shown any of these functions. Further genetic mutation experiments should disclose the role of these filaments in the near future.

\section{The cytoskeleton in inflammation OXIDATIVE STRESS}

During activation of neutrophils at an inflammatory site, or after hypoxic reperfusion events, or both, reactive oxygen species are generated. Superoxide $\left(\mathrm{O}_{2}^{-}\right)$is generated from NADH oxidase and can dismutate to form hydrogen peroxide $\left(\mathrm{H}_{2} \mathrm{O}_{2}\right)$. This may then react with superoxide when catalytic iron (or another redox active metal) is present to produce the highly reactive hydroxyl radical by means of the Fenton reaction. ${ }^{32}$

Oxidative stress perturbs several cellular functions-namely, (a) ATP and NAD depletion; (b) $\mathrm{Ca}^{2+}$ influx; (c) activation of ADP polyphosphate; $(d)$ thiol redox status; $(e)$ the glyceraldehyde-3-phosphate by oxidation of a critical thiol. ${ }^{33}$

Actin structures are disrupted during oxidative stress induced by $\mathrm{H}_{2} \mathrm{O}_{2} \cdot{ }^{34}{ }^{35}$ It should be borne in mind, however, that the concentrations of $\mathrm{H}_{2} \mathrm{O}_{2}$ used were high, leading to cell mortality. Nevertheless, this actin disruption caused a loss of cellular organisation with membrane blebbing and cell rounding. Of the several important cell functions affected during this process-for example, $\mathrm{Ca}^{2+}$ influx, ATP depletion, and thiol oxidation, all are known to affect microfilaments.

There are, however, a large number of actin associated proteins, some of which are regulated by $\mathrm{Ca}^{2+}$ and phosphorylation, which control microfilament structure and may be perturbed during oxidative stress, leading to microfilament disruption. We have shown that intermediate filaments are also susceptible to oxidative stress. At high concentrations of $\mathrm{H}_{2} \mathrm{O}_{2}$ $(100 \mu \mathrm{mol} / \mathrm{l})$ activation of a $\mathrm{Ca}^{2+}$ dependent, vimentin specific proteinase occurs. ${ }^{36}$ This cleaves the $\mathrm{N}$-terminal region which is important for filament formation. At lower concentrations $(25 \mu \mathrm{mol} / \mathrm{l})$, when no loss in cell viability occurs, the major factor seems to a blocking of the sole cysteine in vimentin, possibly by reduced glutathione. ${ }^{37}$ The effect of this is to produce a collapse of these filaments around the nucleus. Furthermore, rheumatoid synoviocytes are more susceptible to this collapse than other control cells (human skin fibroblasts). Interestingly, various other stress phenomena (such as heat shock) also produce this collapse. ${ }^{38}$

The effect of oxidative stress in vivo on microtubules seems to be undocumented. In vitro oxidation, however, does render tubulin incapable of forming microtubules. ${ }^{39} \mathrm{~A}$ number of studies have been carried out to show the effect of reduced cellular glutathione on these structures. ${ }^{40-42}$ Glutathione depletion leads to complete disassembly which would, therefore, seem to involve thiol groups. It is also likely that the high susceptibility to $\mathrm{Ca}^{2+}$ is important. Recent work has shown that low concentrations of $\mathrm{H}_{2} \mathrm{O}_{2}$ can lead to changes in gene expression through activation of the transcription factor NF-kB from its inactive cytoplasmic form. This raises the possibility that some cytoskeletal alterations are due to the presence of newly transcribed gene products within the cell. ${ }^{43}$

\section{HYPOXIA/REPERFUSION}

In the inflamed joint abnormally high pressures are generated during exercise ${ }^{44}$ causing the closure of the synovial capillary beds. The joint is subjected to repeated hypoxic (ischaemic) reperfusion events. ${ }^{45}$ Hypoxia/reperfusion has been reviewed elsewhere, but little attention has been paid to effects on the cytoskeleton. The limited amount of data available, however, suggests that the cytoskeleton is very susceptible to perturbation during such events. ${ }^{46}$ It is likely that the $\mathrm{Ca}^{2+}$ influx, $\mathrm{O}_{2}^{-}$generation by xanthine 
oxidase, or ATP depletion are all important in this process. These effects are apt to be directed to the endothelial cells.

\section{A CRITICAL ROLE FOR THE ENDOTHELIAL CELL} CYTOSKELETON

Inflammation is associated with an increase in vascular permeability to macromolecules, particularly in the postcapillary venules. ${ }^{47}$ Such permeability is thought to be the result of interendothelial cell gap formation following endothelial cell contraction. ${ }^{48}$ Normal microfilament structure is required for retention of cell shape, and disruption may therefore be of particular importance in the microvascular endothelial cells. For example, inflammagens, such as histamine, neuropeptides, bradykinin, prostaglandins, leukotrienes, and thrombin, have all been shown to increase vascular permeability, and a number of them also cause changes in large vein endothelial cell shape. ${ }^{49}$ Their effect is caused, at least in part, by second messenger activation, which acts on several cytoskeleton components. Calcium has a potent effect on microtubules and several microfilament associated proteins, whereas cAMP induces phosphorylation of vimentin rendering it assembly incompetent. ${ }^{50}$ This results in changed cellular morphology and disruption of intercellular contacts. It is interesting to speculate that such changes are associated with the production of high endothelial venules, which are important in lymphocyte trafficking into synovial tissue. ${ }^{51}$

In vivo studies have shown that the influx of polymorphonuclear leucocytes into pulmonary tissue increases when the actin cytoskeleton is rearranged. ${ }^{52}$ Possibly, also the actin microfilaments regulate surface adhesion molecules such as the integrins with which they are known to be closely associated. ${ }^{53}$ The importance of microfilaments in the control of cell permeability has been shown by Hecht $e t$ al, who treated cell monolayers with the toxin A of Clostridium difficile (which causes severe inflammatory enterocolitis in man) and produced an increase in transcellular transport and oedema. ${ }^{54}$ Furthermore, the increase in permeability in this model is correlated with the disruption of the actin microfilaments. This correlation did not occur when permeability was induced with $\mathrm{Ca}^{2+}$ or 8 -bromo-cAMP.

Other studies also indicate that cytoskeleton integrity is essential for maintenance of the endothelial intercellular tight junction and control of vascular permeability. It is therefore possible to modulate permeability by using such agents as phalloidin (a fungal toxin which stabilises and increases actin polymerisation, and cytochalasin $B$ (which induces actin disassembly) in vivo. ${ }^{9}$ Goldman et al have recently produced in vivo data showing that microfilaments are important in controlling polymorphonuclear leucocyte infiltration in a rat lung model. In this model phalloidin decreased leucocyte infiltration induced by leukotriene $\mathrm{B}_{4} .{ }^{51}$ Cytochalasin B had an opposite effect and this could be inhibited by phalloidin. It has also been shown that microfilaments are involved in the movement of organelles, and this function may also be restricted after actin filament disruption.

\section{NEUTROPHIL DEACTIVATION}

Activation of neutrophils by chemotactic agents induces changes, cell shape, migration, degranulation, and phagocytic responses, all of which require cytoskeletal restructuring. ${ }^{55}$ In addition, superoxide production by NADPH oxidase is also regulated by microfilaments. For example, it has been shown that cytochalasin B drastically increases $\mathrm{O}_{2}^{-}$production after stimulation with $N$-formyl-methionyl-leucyl-phenylalanine (fMLP), platelet activating factor, and concanavalin A. ${ }^{56}$ Botulinum $\mathrm{C} 2$ toxin (which ADP-ribosylates $\mathrm{G}$ actin) has also recently been shown to produce the same effect. ${ }^{57}$ Interestingly, both these compounds inhibit actin polymerisation. The precise mechanism by which this occurs is unknown, though the ligand-occupied fMLP receptor associates very rapidly with the cytoskeleton ${ }^{58}$ and may therefore produce a desensitising effect. Association of the receptor-ligand with the microfilaments stops the signal for cell activation by termination of second messenger production. This would therefore represent a negative feedback mechanism as the production of the second messengers $\mathrm{IP}_{3}$ and diacylglycerol causes disruption in the actin cytoskeleton.

Data presented by Sarndahl show that a $\mathrm{G}$ protein interaction is involved. ${ }^{59} \mathrm{He}$ also suggests that a binding site for actin is produced by a conformational change when either the $\alpha$ or $\beta$ subunits dissociate from the $G$ protein complex. Any disruption of this feedback mechanism could induce massive production of $\mathrm{O}_{2}^{-}$when the cell is activated owing to the fact that the cell is unable to terminate the signal produced at its surfaces. This general mechanism may also be of relevance to other receptorligand responses in other cells-for example, in endothelial cells.

\section{AUTOANTIBODIES}

Autoantibodies to cytoskeletal proteins occur in rheumatoid arthritis and in other connective tissue disorders, such as Sjögren's syndrome and systemic lupus erythematosus. ${ }^{60}$ The presence of antibodies to intermediate filament is particularly widespread; antibodies to vimentin occurring in up to $80 \%$ of patients with rheumatoid arthritis. ${ }^{61}$

Use of these antibodies for diagnostic purposes is hampered by the lack of specificity as they occur in $12 \%$ of apparently normal subjects. The antibodies are of the IgG and IgM classes. ${ }^{62}$ The biological relevance of these antibodies remains obscure as does the mechanism by which they arise. Indeed whether they are protective or damaging is still open to speculation. Possibly, for example, they prevent the overactivation of complement by aiding opsonisation and removal of intermediate filaments. Conversely, they may direct the immune system to such filaments. Further studies on antibody subtyping may throw some light on this matter. 
For example, it has been shown that antibodies to keratin are significantly higher in IgGl and lower in IgG2.64 There is also a high prevalence of IgG4 possibly owing to chronic exposure to the protein antigen. There is evidence that subclasses of antibodies occur, some of which cross react with other cellular antigens, such as DNA and cardiolipin. ${ }^{64}$

Sanchez et al have recently shown that a particular subset of antibodies from patients with systemic lupus erythematosus reacts with DNA and vimentin. ${ }^{65}$ These antibodies are specific for IgM and possibly, therefore, some classes only occur in particular diseases, providing a useful diagnostic test.

In rheumatoid patients the epitope with which the antibodies react is unknown, but efforts made to locate this may be rewarding diagnostically.

In acute proliferative glomerulonephritis, which occurs after streptococcal infection, cross reactive antibodies are present that react with a different epitope on type $1 \mathrm{M}$ and type $12 \mathrm{M}$ streptococcal proteins and with vimentin. ${ }^{66}$ In type $1 \mathrm{M}$ proteins the epitope has been mapped to a tetrapeptide which occurs at the $\mathrm{N}$-terminal side of a helical part of the rod domain of vimentin. It is noteworthy that the epitope in the type $1 \mathrm{M}$ protein is also a helical coiled coil (cf structure of intermediate filaments). Interestingly, our data show that rheumatoid serum samples react with epitope(s) present within a 20 kilodalton region of the central core domain which also contains this tetrapeptide sequence. ${ }^{67}$ Also, autoantisera which react with antigens in placental extracts have recently been described. ${ }^{68}$ On western blots, these antigens occur mainly at 48 kilodaltons with several smaller molecular weight bands which are characteristic of vimentin degradation by a $\mathrm{Ca}^{2+}$ dependent proteinase. Moreover, the authors claim that this reactivity is $100 \%$ specific for rheumatoid patients. If the autoantisera were directed against vimentin it is difficult to explain the $100 \%$ specificity. One possibility is that reactivity is directed against a postranslationally modified protein and may therefore represent a subpopulation of antibodies that react with epitopes in vimentin. If this were the case there would be obvious clinical and diagnostic implications.

THE SYNOVIAL LINING CELL

The rheumatoid synovium is characterised by a proliferation of B type synoviocytes, which possess fibroblastic morphology ${ }^{69}$ and have a vast increase in the $10 \mathrm{~nm}$ vimentin intermediate filaments in the cytosol. ${ }^{70}$ The cause of this is at present unknown, but a number of circulating factors have been shown to increase vimentin expression. ${ }^{71} 72$ Vimentin is also a growth regulated gene, which is upregulated after oncogene activation. ${ }^{71}$ The ras oncogene when transfected into myoblasts causes the continual expression of vimentin. ${ }^{72}$ Two other transforming factors also increase vimentin expression: $\operatorname{tax}(\mathrm{p} 40 \mathrm{x})$ protein of human $\mathrm{T}$ cell leukaemia virus type 1 and the SV40 T antigen. ${ }^{73}$ The 19 kilodalton product of the adenovirus EIB oncogene also associates with vimentin intermediate filaments and specifically disrupts this class of cytoskeleton filament. ${ }^{74}$

Interestingly, the protooncogene $\mathrm{dbl}$ shows a high degree of homology with the vimentin protein in the $\alpha$ helix coiled coil structure and contains the heptad repeat motif. ${ }^{75}$ It is logical to postulate that the proliferation and increase in vimentin content in the cell are linked. The possibility arises that this may be due to an oncogene activation in the proliferating cell. As discussed above NF-kB, which is highly related to c-rel oncogene, is activated in Jerkat cells exposed to $\mathrm{H}_{2} \mathrm{O}_{2}$. Low concentrations of $\mathrm{H}_{2} \mathrm{O}_{2}$ also induce cell proliferation and it is interesting to speculate that this is induced by the activation of NF-kB, which leads to activation of specific gene products. ${ }^{43}$

\section{COMPLEMENT ACTIVATION}

When tissue sections or fixed cells are incubated with normal serum, binding of complement components ( $\mathrm{Clq}, \mathrm{C} 4$, and $\mathrm{C} 3$ ) to the intermediate filaments occurs specifically. ${ }^{76}$ This binding is rapid for $\mathrm{Clq}$ (within 10 seconds) and causes activation through the classical pathway. Accumulation of $\mathrm{C} 3$ takes up to several minutes. The $\mathrm{C} 3$ binding may be through the alternative pathway and is independent of antibodies (but see also below).

Activation of complement causes degradation of the intermediate filaments, which are highly sensitive to proteolysis. ${ }^{77}$ Intermediate filaments are, therefore, endogenous activators of complement. It has been shown that monocytes can bind to cells which have been previously incubated with serum and that such monocyte binding is closely associated with intermediate filament structures. ${ }^{78}$ The binding is inhibited by $\mathrm{Ca}^{2+}$ chelators, indicating that some of the binding may occur by receptors on the monocytes recognising $\mathrm{C} 3 \mathrm{~b}$ and $\mathrm{C} 3 \mathrm{bi}$. Possibly, also, there is binding through $\mathrm{Clq}$ as there is also a receptor (on monocytes) for this component. Hansson has shown that vimentin filaments, but not monomeric vimentin, on western blots possess high affinity saturable binding sites. for IgG. This occurs through the Fc portion of the IgG molecule and most probably in the $C \gamma^{2}$ domain. This is independent of the autoantibodies discussed above. In endothelial cells, IgG aggregates have been shown to be closely associated with intermediate filaments in vivo. ${ }^{79}$ Furthermore, intermediate filaments activate complement by formation of complexes with IgG Clq. In vivo, therefore, monocyte binding may help in the removal of exposed intermediate filaments or non-viable damaged cells by opsonisation. A prerequisite for this mechanism is damage at the plasma membrane, and viable cells would, therefore, be unaffected, producing a self regulating system. This process occurs in non-pathological tissue and therefore functions in normal cell turnover. ${ }^{80}$ When tissue damage occurs an increase in monocyte recruitment is required, and this probably occurs as a result of the release of chemotactic factors during complement activation. Recruitment of monocytes will obviously be particularly important 
after endothelial cell damage as there is direct contact with circulating monocytes.

Overactivation of these mechanisms may cause accumulation of monocytes and tissue damage at sites of inflammation. The presence of large quantities of vimentin intermediate filaments in rheumatoid synovial cells may be important as removal of unviable cells would need a greater recruitment of monocytes, again leading to tissue destruction/inflammation.

Vitronectin has recently been shown to bind cytokeratin intermediate filaments and it is suggested that the vitronectin stops overactivation of the complement mechanism discussed above. This is an attractive proposal, and it is intriguing to speculate that in some pathological conditions this regulatory system may be aberrant. ${ }^{81}$

\section{POSSIBLE DRUG INTERVENTION}

In this review we have shown that the cytoskeleton has an important and complex role in inflammatory processes. There is, therefore, the possibility that new drugs can be developed to gain therapeutic advantage. It may be possible to reduce oedema by the use of drugs that decrease the sensitivity to $\mathrm{Ca}^{2+}$ influx. The problem with this approach, however, is that such drugs would have a non-specific effect, and as microfilaments are important to cellular function, toxicity might be a problem. One way to negate this would be to direct drug action to the capillary bed. This could be achieved by designing compounds which alter those microfilament associated proteins that are specifically expressed in such cells. These drugs would not, therefore, affect normal cellular function.

As discussed above, thiols are important in maintaining the normal cytoskeleton. It is well documented that there is a decrease in free thiol in rheumatoid serum. We have also shown that disodium aurothiomalate, an antiarthritic drug which is thiol reactive, produces similar effects to those of hydrogen peroxide exposure-that is, a collapse in the vimentin structures around the nucleus. This drug also prevents cell proliferation and derives a therapeutic effect by inhibition of the proliferating synovial lining cell. It is also attractive to speculate that this effect is mediated through binding to critical thiols in the cytoskeleton. It may therefore be advantageous to produce drugs that bind to such thiols specifically.

\section{Conclusion}

The cytoskeleton is quite clearly involved in a vast array of vital cellular functions. Many of these also have a pronounced influence on the inflammatory process. This area has received little attention thus far. Future research will undoubtedly disclose new inflammatory processes influenced by the cytoskeleton. Furthermore, a better understanding of these processes will enable the design of truly new therapeutic compounds.

We thank the Arthritis and Rheumatism Council for Research for supporting this work.
1 Schliwa M. Microfilaments. Microtubules. Intermediate filaments. In: Ifert M, Beermann W, Goldstein R D, eds. The cytoskeleton: an introductory survey. Vienna, New York: Springer, 1986: 1-115.

2 Vikstom K L, Borisy G G, Goldman R D. Dynamic aspects of intermediate filament networks in NHK-21 cells. Proc Natl Acad Sci USA 1989; 86: 549-53.

3 Vandekerkove J, Weber K. At least six different actins are expressed in a higher mammal: an analysis on the amino acid sequence of the aminoterminal peptide. $7 \mathrm{Mol} \mathrm{Biol}$ 1978; 126: 783-802.

4 Cooper J A, Buhle E L, Walker S B, Tsong T Y, Pollard T D. Kinetic evidence for a monomer activation step in actin polymerisation. Biochemistry 1983; 22: 2193-202.

5 Sanders M C, Wang Y. Exogenous nucleation sites fail to induce detectable polymerization of actin in living cells. f Cell Biol 1990; 110: 359-65.

6 Egelman $\mathrm{E} \mathrm{H}$. Helical disorder and the filament structure $\mathrm{F}$ actin are elucidated by angle-layered aggregates. $7 \mathrm{Mol} \mathrm{Biol}$ 1990; 166: 60-2.

7 Way M, Weeds A. Cytoskeletal ups and downs. Nature 1990 344: 292-3.

8 Mejean C, Pons F, Benyamin Y, Roustan C. Antigenic probe locate binding sites for the glycolytic enzymes glyceraldehyde-6-phosphate dehydrogenase, aldolase and phosphohyde-6-phosphate dehydrogenase, aldolase and phosphofructokinase on actin

9 Cooper J A. Effect of cytochalasin and phalloidin on actin F Cell Biol 1987; 105: 1473-8.

10 Virtanen I, Vartio T, Badley R A, Lehto V P. Fibronectin in adhesion, spreading and cytoskeletal organisation of cultured fibroblast. Nature 1982; 298: 660-3.

11 Forcher P. Calcium and polyphosphoinositide control of cytoskeletal dynamics. Trends Neurosci 1989; 12: 468-74.

12 Tucker J B. Spatial organisation of microtubule-organisin centres and microtubules. 7 Cell Biol 1986; 99: 55s-62s.

13 Tucker,J B. Spatial organisation of microtubules. 1984: In: Roberts K, Hyams J S, eds. Microtubules. London: Academic Press, 1984: 315-58.

14 Tilney L G, Bryan J, Bush D J, Fujiwara N, Mooseker M S Murphy D B. Microtubules: evidence for 13 subunit protofilaments. F Cell Biol 1973; 59: 267-75.

15 Carlier M F. Kinetic evidence for a conformation change of tubulin preceding microtubule assembly. I Biol Chem 1984; 258: 2415-20.

16 Gupta R S. Mitochondria, molecular chaperone proteins and the in vivo assembly of microtubules. Trends Biochem Sci 1990; 15: 415-8.

17 Kumagai $\mathrm{H}$, Sakai $\mathrm{H}$. The interaction between calmodulin and microtubule protein. Quantitative analysis of the binding between calmodulin and tubulin dimers. 7 Biochem 1982; 93: 1259-336.

18 Matter K, Bucher K, Hauri H. Microtubule pertubation retards both the direct and the indirect apical pathway but does not affect sorting of plasma membrane proteins in intestinal epithelial cells (Caca-2). EMBO f 1989; 8 : 3163-70.

19 Mitchison T, Kirschner M. Microtubule assembly nucleated by isolated centrosomes. Nature 1984; 217: 1053-4.

20 Steinart P M, Rot D R. Molecular and cellular biology of intermediate filaments. Ann Rev Biochem 1988; 57: 593-625.

21 Lazarides E. Intermediate filaments. A chemically heterogeneous developmentally regulated set of proteins. Ann Rev Biochem 1982; 51: 219-50.

22 Osborn $M$, Weber $K$. Intermediate filament proteins: a multigene family distinguishing major cell lineages. Trend Biochem Sci 1986; 11: 469-72.

23 Renner W. Reconstitution of intermediate-sized filaments rom denatured monomeric vimentin. $7 \mathrm{Mol} \mathrm{Biol} \mathrm{1981}$ 149: 285-306.

24 Traub P, Vorgias C E. Differential effect of arginine modification with 1,2-cyclohexanedione on the capacity of vimentin and desmin to assemble into intermediate and to bind to nucleic acids. F Cell Sci 1984; 65: 1-20.

25 Quinlan R A, Moir D, Stewart M. Assembly important domains in type III intermediate filament proteins. $\mathcal{f}$ Cell Biol 1989; 93: 71-83.

26 Soellner P, Quinlan R A, Franke W W. Identification of a distinct soluble subunit of an intermediate filament protein tetrameric vimentin from living cells. Proc Natl Acad S $\mathrm{c}$ USA 1985; 82: 7929-33.

27 Sarria A J, Nordeen S K, Evans R M. Regulated expression of vimentin cDNA in cells in the presence and absence of pre-existing vimentin filament network. F Cell Biol 1990; pre-existing ving $553-65$.

28 Georgatos S, Blobel V. Two distinct binding sites for vimentin along the plasma membrane and the nuclea membrane in avian erythrocytes: A basis for vectorial assembly of intermediate filaments. $\mathcal{F}$ Cell Biol 1987; 105 : $105-15$

29 Bloemendal H, Pieper F R. Intermediate filaments: known structure, unknown function. Biochem Biophys Acta 1989, 1007: 245-53

30 Shoeman $R$ L, Traub $P$. The in-vitro DNA-binding properties of purified nuclear lamin protein and vimentin. $\mathcal{F}$ Biol Chem 1990; 265: 9055-61.

31 Lazarides E. Intermediate filaments as mechanical integrators of cellular space. Nature 1980; 283: 12 .

32 Fenton $\mathrm{H} \mathrm{J} \mathrm{H}$. Oxidation of tartaric acid in presence of iron. f Chem Soc 1984; 65: 899-910.

33 Hyslop A P, Hinshaw D B, Halsey W A. Mechanisms of oxidant-mediated cell injury. $\mathcal{F}$ Biol Chem 1988; 263: $1665-75$. 
34 Hinshaw D B. Cytoskeletal and morphologic impact of cellular oxidant injury. Am f Pathol 1986; 123: 454-64.

35 Mirabelli F. Menadione-induced bleb formation in hepatocytes is associated with the oxidation of thiol groups in actin. Arch Biochem Biophys 1988; 264: 261-9.

36 Rogers K R, Morris C J, Blake D R. Stress stimuli and cytoskeleton rearrangement. In: Rice-Evans $\mathrm{C}$, Winrow $\dot{V} \mathrm{R}$, Burdon $\mathrm{R}$, Blake $\mathrm{D} \mathrm{R}$, eds. Stress proteins i inflammation. London: Richelieu Press, 1990: 369-80.

37 Rogers K R, Morris C J, Blake D R. Oxidation of thiol in the vimentin cytoskeleton. Biochem $\mathcal{F}$ 1991; 275: 789-91.

38 Blessman H, Falker F G, Saumweber H, Walter M F. 1982 In Schlesinger M J, Ashburner S, Tissiers A, eds. Heo shock: from bacteria to man. New York: Cold Spring Harbour Laboratory, 1982: 275-81.

39 Mellon M G, Rebhun L I. Sulphydryls and the in vitro polymerisation of tubulin. F Cell Biol 1976; 70: 226-38.

40 Leung M F, Chou I N. Effect of glutathione depletion on the cytoskeleton. Cell Biol Toxicol 1989; 3: 51-66.

41 Oliver M, Albertini D F, Berlin R D. Effect of glutathioneoxidizing agents on microtubular assembly and microtubular-dependent surface properties of human neutrophils. f Cell Biol 1988; 71: 921-32.

42 Kromidas L, Trombetta L D, Jamall I S. The protective effect of glutathione against methylmercury cytotoxicity. Toxicol Lett 1990; 51 : 67-80.

43 Schreck R, Rieber P, Baeuerle P A. Reactive oxvgen intermediates are apparently widely used messengers in the activation of the NF-kB transcription factor and HIV-1. EMBO f 1991; 10: 2247-58.

44 Stevens C R, Williams R B, Farrell A J, Blake D R. Hypoxia and inflammatory synovitis: observations and speculation. Ann Rheum Dis 1991; 50: 124-32.

45 Blake D R, Merry P, Unsworth J. Hypoxic-reperfusion injury in the inflamed human joint. Lancet $1989 ; i ; 289-93$.

46 Sage M D, Jenning R B. Cytoskeletal injury and subsarcolemmal bleb formation in dog heart during in vitro total ischaemia. A m F Pathol 1988; 133: 2-7.

47 Shasby D M, Shasby S S, Sullivan J M, Peach M J. The role of the endothelial cell cytoskeleton in the control of endothelial permeability. Circ Res 1982, 51: 6577-81.

48 Svensio E, Grega G J. Evidence for endothelial cell mediated regulation of macromolecular permeability by post capillary venules. Fed Proc 1986; 45: 89-95.

49 Northover A M, Northover B J. The effect of histamine, 5 hydroxy-tryptamine and bradykinin on rat mesenteric blood vessels. F Pathol 1969; 98: 265-9.

50 Inagaki $M$. Phosphorylation sites linked to glial filamen disassembly in vitro locate in a non-ct-helical head domain. f Biol Chem 1990; 265: 4722-9.

51 Goldman G, Welbourn R, Alexander S, et al. Modulation of pulmonary permeability in vivo with agents that affect the pulmonary permeability in vivo with agents
cytoskeleton. Surgery 1990; 109: $533-38$.

52 Gowans J L. Knight E J. The route of recirculation of lymphocytes in the rat. Proc $R$ Soc Lond [Biol] 1964; 159. lymphocyte $257-82$.

53 Geisow M J, Critchley D R. Plasma membrane-cytoskeleton interaction in normal and transformed cells. Biochem So Trans 1987; 15: 789-95.

54 Hecht G, Pthoulakis C, Lamont J T, Madara J L. Clostridium difficile toxin perturbs cytoskeletal structure and tigh junction permeability of cultured human intestina epithelial monolayers. F Clin Invest 1988; 82: 1516-24.

55 Omann G M, Allen R A, Bokoch G M. Signal transduction and cytoskeletal activation in the neutrophil. Physiol Rev 1987; 67: 285-322.

56 White J R, Naccache P H, Shaafi R I. Stimulation by chemotactic factor of actin association with the cytoskeleton in rabbit neutrophils. 7 Biol Chem 1983; 258: 14041-7.

57 Norgauer J, Kownatazki E, Seifert R. Botulinum C2 toxin ADP-ribosylates actin and enhances $\mathrm{O}_{2}^{-}$production and ADP-ribosylates actin and enhances $\mathrm{O}_{2}^{-}$production and secretion but' inhibits migration of activ
phils. F Clin Invest 1988; 82: 1376-82

58 Jesaitis A J, Tolley J O, Allen R A. Receptor-cytoskeleton interactions and membrane traffic may regulate chemoattractant-induced superoxide production in huma granulocytes. F Cell Biol 1986; 261: 13662-9.

59 Sarndahl E. Association of ligand-receptor complexes with actin filament is in human neutrophils: a possible regulatory role for a G-protein. 7 Cell Biol 1989; 109: 2791-9.
60 Kurki P, Virtanen I. The detection of human antibodies against cytoskeletal components. F Immunol Methods 1984 67: 209-23.

61 Kurki P, Helve T, Virtanen I. Antibodies to cytoplasmic intermediate filament in rheumatic diseases 7 Rheumatol intermediate filam

62 Osung $\mathrm{O}$ A, Chandra M, Holborow E J. Antibodies to intermediate filaments of the cytoskeleton in rheumatoid arthritis. Ann Rheum Dis 1982; 41: 69-73.

63 Vincent C, Serre G, Basile J P. Subclass distribution of IgG antibodies to the rat oesophagus stratum corneum (so called anti-keratin antibodies) in rheumatoid arthritis. (Clin Exp Immunol 1990; 81: 83-9.

64 Blaschek M A. Relation of antivimentin antibodies to anticardiolipin antibodies in systemic lupus ervthematosus. Ann Rheum Dis 1988; 47: 708-16.

65 Sanchez A, Ossorio C, Alvaro-Gracia J M, Padilla R, Avila J. A subset of antibodies from the sera of patients with systemic lupus erythematosus react with vimentin and DNA. I Rheumatol 1990; 17: 205-9.

66 Kraus W, Seyder J M, Beachey E H. Vimentin cross-reactive epitope of type 12 streptococcal $M$ protein. Infect Immun epitope of type 12

67 Rogers K R, Morris C J, Blake D R. Autoantibodies to vimentin react with a $38 \mathrm{kD}$ central domain region. $\mathrm{Br} . \mathcal{7}$ Rheumatol 1990;29 (suppl 2): 19

68 Lopez-Longo F J, Monteagudol F, Ariza A, Alonso J, Carreno L. Clinical significance of anti Sa antibodies: a novel rheumatoid arthritis marker. Br $\mathcal{F}$ Rheumatol 1990 29: (suppl 2): 18.

69 Hollywell C, Morris C J, Farr M, Walton K W. Ultrastructure of synovial changes in rheumatoid disease and in seronegative inflammatory arthropathies. Virchows Arch [Path Anatl 1983; 400: 345-55.

70 Osung O A, Chandra M, Holborow E J. Intermediate filaments in the synovial lining cells in rheumatoid arthritis and other arthritides are of vimentin type. Ann Rheum $D i$ 1982; 41: 74-7

71 Ferrari $S$. Ratios between the abundance of messenger RNA and the corresponding protein of two growth related genes c-myc and vimentin

72 Olson E N, Capetanaki Y G. Developmental regulation of intermediate filament and actin mRNAs during myogenesis is disrupted by oncogenic ras genes. Oncogene 1989; 4: is disrup $907-13$.

73 Lilienbaum A, Dodon M D, Alexander C, Gazzolo L, Paulin D. Effect of human T-cell leukemia virus type I tax protein on activation of the human vimentin gene. 7 Virol $1990 ; 43$ : 256-63.

74 White E, Cipriani R. Specific disruption of intermediate filament and the nuclear lamina by the 19-kDa product of the adenovirus E1B oncogene. Proc Natl Acad Sci USA 1989; 86: 9886-90.

75 Ron D, Tronick S R, Aaronson Eva A, Molecular cloning and characterisation of the human $\mathrm{dbl}$ proto-oncogene: evidence that its over expression is sufficient to transform NIH 3 T 3 cells. EMBO f $1988 ; 7: 2465-73$

76 Linder E. Binding of $\mathrm{Cla}$ and complement activation by vascular endothelium. F Immunol 1980; 126: 648-58.

77 Hansson G K, Langerstedt E, Bengtsson A, Heideman M. IgG binding to cytoskeletal intermediate filaments activates
the complement cascade. Exp Cell Res 1987; 170: 338-50.

78 Linder E, Chang C, Edgington T S. Complement-mediated binding of monocytes to intermediate filaments in vitro. Am 7 Pathol 1983; 112: 267-77.

79 Hansson G K, Bondjers G, Bylock A, Hjalmarsson L. Ultrastructural studies on the location of IgG in the aortic endothelium and subendothelium intima of atherosclerotic and non-atherosclerotic rabbits. Exp Mol Pathol 1985; 33: 302-31.

80 Hansson G K, Starkebaum G A, Benditt E P, Schwartz S M. Fc-mediated binding of IgG to vimentin type intermediate filaments in vascular endothelial cells. Proc Natl Acad Sci USA 1984; 81: 3103-7.

81 Hinter H, Stazl U, Dahlback K. Vitronectin shows complement independent binding to isolated keratin filament aggregates. F Invest Dermatol 1989; 93: 656-61. 